\title{
Analisis Pemetaan Ruang Terbuka Hijau dari Hasil Citra Landsat 8 Menggunakan Metode NDVI di Kota Malang
}

\author{
Erlinda Dwita Nurlaily ${ }^{1}$, Lis Diana Mustafa ${ }^{2}$, Putri Elfa M. ${ }^{3}$ \\ ${ }^{1}$ Program Studi Jaringan Telekomunikasi Digital, \\ Jurusan Teknik Elektro, Politeknik Negeri Malang, Indonesia \\ 2,3 Program Studi Teknik Telekomunikasi, \\ Jurusan Teknik Elektro, Politeknik Negeri Malang, Indonesia \\ 1erlindaer354@gmail.com, ${ }^{2}$ lisdianamustafa16@gmail.com, ${ }^{3}$ putri.elfa@polinema.ac.id
}

\begin{abstract}
This study utilizes Landsat 8 satellite imagery using image processing techniques ranging from radiometric correction, image band merging, and image cutting to obtain the area to be analyzed, namely Malang City. To obtain green open space data in the research area, the NDVI method was chosen as the method. The vegetation density is divided into several classes. The image processing results are compared with the results of field tests using google street view to determine whether the results of the analysis are accurate. The results of the analysis obtained were then made a Decision Support System with the SAW method. This study's output was the creation of an android application containing information systems about green open space in Malang City and recommendations for actions for the benefit of green open space management in Malang City. The system created based on the 2020 image analysis resulted in adding green open space needed in 3 sub-districts, namely Klojen District, Sukun District, and Blimbing District. Meanwhile, the data's accuracy in this study amounted to $86 \%$ of the overall data analyzed. In 2016 the total area of green open space was $17.81 \%$, in 2017 , the area of green open space was $15.57 \%$, in 2018, there was a significant increase in the area of green open space by $27.92 \%$, in 2019 the area of green open space was $17.43 \%$, and in 2020 , the area of green open space is $17.18 \%$ of the total area of Malang City.
\end{abstract}

Keywords - RTH, Landsat Satellite, NDVI, Image Processing, SAW.

Abstrak - Penelitian ini memanfaatkan citra Satelit Landsat 8 menggunakan beberapa teknik pengolahan citra mulai dari koreksi radiometrik, penggabungan band citra, dan juga pemotongan citra untuk memperoleh wilayah yang akan dianalisis yaitu Kota Malang. Untuk memperoleh data RTH diwilayah penelitian metode NDVI dipilih sebagai metode. Kerapatan vegetasi dibagi menjadi beberapa kelas. Hasil dari pengolahan citra tersebut dibandingkan dengan hasil uji lapangan menggunakan google street view untuk mengetahui apakah hasil analisisnya akurat. Hasil analisis yang didapat kemudian dibuat Sistem penndukung Keputusan dengan metode SAW Output dari penelitian ini adalah dibuatnya aplikasi android yang berisikan tentang sistem informasi seputar RTH di Kota Malang serta rekomendasi tindakan untuk kepentingan pengelolaan RTH di Kota Malang. Sistem yang dibuat berdasarkan analisis citra tahun 2020 menghasilkan rekomendasi keputusan Penambahan RTH diperlukan di 3 kecamatan yaitu Kecamatan Klojen, Kecamatan Sukun dan Kecamatan Blimbing. Sedangkan, keakurasian data pada penelitian ini adalah sebesar $86 \%$ dari keseluruhan data yang dianalisis. Pada tahun 2016 total luasan RTH yaitu 17,81\%, tahun 2017 luasan RTH sebesar 15,57\%, tahun 2018 terdapat perningkatan yang cukup signifikan luas RTH sebesar $27,92 \%$, tahun 2019 luas RTH sebesar $17,43 \%$, dan pada tahun 2020 luas RTH yaitu sebesar $17,18 \%$ dari luas total Kota Malang.

Kata kunci- RTH, Satelit landsat, NDVI, Pengolahan Citra, SAW.

\section{PENDAHULUAN}

Definisi dari Ruang Terbuka Hijau (RTH) atau dalam bahasa inggris Green Open Space menurut Undang-undang No 26 Tahun 2007 adalah area memanjang/jalur dan/atau mengelompok, yang penggunaannya lebih bersifat terbuka, dikatakan 'hijau' karena RTH menjadi tempat tumbuh tanaman, baik yang tumbuh secara alamiah maupun yang sengaja ditanam, biasanya tempat ini berupa taman yang terletak di tengah kota[1][2].

Hingga akhir tahun 2017 ketersediaan Ruang Terbuka Hijau di kota Malang hanya mencapai $17 \%$, data ini diperoleh dari Dinas Perumahaan dan Kawasan Permukiman (Diperkim) kota Malang. Hal ini dinilai sangat jauh dari standar seharusnya ketersediaan RTH di suatu kota, karena berdasarkan Peraturan Menteri (Permen) PU No. 05/prt $/ \mathrm{m} / 2008$ tentang pedoman penyediaan Ruang Terbuka Hijau di kawasan perkotaan disebutkan bahwa jumlah RTH suatu wilayah minimal 30 persen dengan pembagian 20 persen RTH publik dan 10 persen privat.

Sebagai upaya untuk meningkatkan ketersediaan RTH di kota Malang diperlukan adanya pemetaan tutpan lahan untuk mengetahui lokasi mana saja yang dinilai membutuhkan peningkatan area resapan air. Untuk melakukan pemetaan lokasi tersebut dikembangkan pengolahan citra dengan penginderaan jauh melalui satelit yang mana teknik ini memiliki jangkauan yang luas. Salah satu satelit yang menghasilkan data citra satelit Landsat 8 dengan metode NDVI (Normalized Difference Vegetation Index) yang merupakan indeks 'kehijauan' vegetasi atau aktifitas fotosintesis vegetasi. Satelit ini berada pada ketinggian $705 \mathrm{~km}$, periode 99 menit, dan waktu liput ulang (resolusi temporal) 16 hari. Dengan satelit ini pemetaan tutupan lahan dapat meliputi RTH, area pemukiman dll. 
Untuk meningkatkan pemantauan ruang terbuka hijau secara berkala maka dibuatlah aplikasi sistem informasi berbasis android. Dari aplikasi ini dapat diketahui informasi luasan kepadatan daerah urban/pemukiman serta luasan ruang terbuka hijau di kota Malang dari tahun ke tahun sehingga dapat dilakukan upaya-upaya untuk menjaga keberadaan ruang terbuka hijau di kota Malang.

\section{METODE}

\section{A. Rancangan penelitian}

Tahapan penelitian mulai dari kajian literatur sampai pembuatan aplikasi ditampilkan pada Gambar 3.1 sebagai berikut:

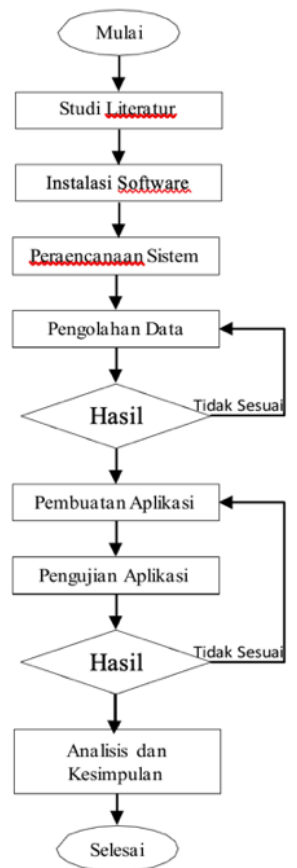

Gambar 1 Flowchart Tahapan Penelitian

\section{B. Blok Diagram}

Proses perancangan sistem yang akan dibuat pada penelitian ini ditunjukkan pada blok diagram berikut:

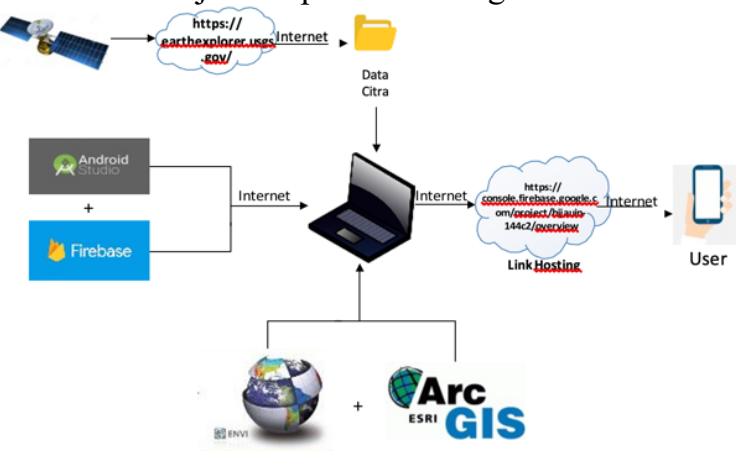

Gambar 2. Blok Diagram Sistem

Data citra diambil dari satelit Landsat 8 yang telah merekam citra permukaan bumi yang kemudian diterima oleh stasiun bumi, data citra dari satelit Landsat 8 yang akan diambil untuk penelitian ini dapat diakses secara gratis melalui website milik USGS dengan alamat www.earthexplorer.com. Data citra kemudian diolah menggunakan beberpa software untuk dapat dianalisa nilai tutupan vegetasinya. selanjutnya dibuat aplikasi android sebagai output dari penelitian yang berisikan sistem informasi mengenai RTH.

\section{HASIL DAN PEMBAHASAN \\ A. Pra Proses Pengolahan Citra}

Sebelum melakukan pengolahan citra tentunya diperlukan data citra itu sendiri yang mana dapat diunduh di laman www.earthexplorer.com pada penelitian ini objek yang diamati adalah kota Malang yang mana terletak pada Path/Row 118/66 dan jenis data yang diunduh adalah "Level-1 GeoTIFF Data Product"

\section{B. Proses Pengolahan Citra}

\section{1) Penggabungan Band Citra}

Pada penelitian ini band yang diperlukan adalah band 654 yaitu untuk kebutuhan analisis vegetasi, penggabungan band citra dapat dilakukan menggunakan software ENVI 5.3 dengan memasukkan 11 fileband citra

2) Koreksi Radiometrik

Proses koreksi radiometrik diperlukan untuk memperbaiki kualitas visual citra dan sekaligus memperbaiki nilai-nilai piksel yang tidak sesuai dengan pantulan dan pancaran spektral obyek yang sebenarnya. Namun apabila minimum citra telah mencapai 0 koreksi radiometrik tidak perlu dilakukan[3].

3) Pemotongan Citra

Data citra yang diunduh dari satelit Landsat 8 masih berupa cakupan wilayah yang cukup besar yaitu berdasarkan path and row sehingga perlu dilakukan pemotongan citra untuk memfokuskan wilayah atau daerah yang akan diteliti. Pada penelitian ini objek yang diamati adalah wilayah administrasi kota Malang, untuk melakukan pemotongan citra tersebut diperlukan file dengan format *.shp yang menunjukkan batas-batas kota Malang.

4) Formula NDVI

Transformasi NDVI memiliki formula sebagai berikut[4]:

$$
N D V I=\frac{\text { Kanal NIR }(\text { band } 5)-\text { kanal RED }(\text { band } 4)}{\text { kanal NIR }(\text { band } 5)+\text { kanal RED }(\text { band } 4)}
$$

Setelah transformasi NDVI diperoleh citra sebagai berikut.

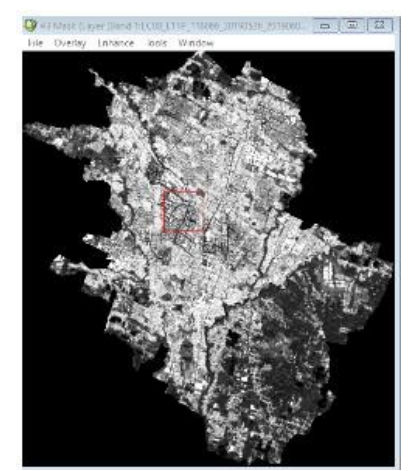

Gambar 3. Hasil Transformasi NDV

Setelah proses transformasi NDVI diperoleh nilai- nilai berikut ini: 
TABEL I

\begin{tabular}{ccc}
\multicolumn{3}{c}{ NILAI NDVI DARI TAHUN KE TAHUN } \\
\hline \multirow{2}{*}{ Tahun } & \multicolumn{2}{c}{ Nilai NDVI } \\
\cline { 2 - 3 } & Min & Max \\
\hline 2016 & $-0,11788$ & 0,299889 \\
\hline 2017 & $-0,242367$ & 0,382022 \\
\hline 2018 & $-0,240444$ & 0,377507 \\
\hline 2019 & $-0,280404$ & 0,35567 \\
\hline 2020 & $-0,253924$ & 0,402196 \\
\hline
\end{tabular}

\section{5) Klasifikasi Citra}

Hasil dari transformasi NDVI yang telah didapat kemudian diklasifikasikan menggunakan metode klasifikasi tidak terbimbing $k$-means, dari proses klasifikasi tersebut diperoleh pembagian klasifikasi sebagai berikut :

TABEL II

PEMBAGIAN KLASIFIKASI VEGETASI [5]

\begin{tabular}{cc}
\hline Klasifikasi & Rentang Nilai NDVI \\
\hline
\end{tabular}

Vegetasi sangat jarang sebagian

besar berupa rumput/lapangan

olahraga/area

$0,1493-0,2257$

pemakaman/ persawahan

\begin{tabular}{lrr}
\hline $\begin{array}{l}\text { Vegetasi sedang } \\
\text { berupa }\end{array}$ & $\begin{array}{l}\text { sebagian besar } \\
\text { semak/tanaman }\end{array}$ \\
perdu/rumput tinggi & $0,2257-0,3022$
\end{tabular}

\begin{tabular}{llll}
\hline Vegetasi lebat & sebagian & berupa & \\
tegakan pohon & & & $0,3022-0,3786$ \\
dari kanopi & sedang & hingga & \\
lebat/hutan kota & & & \\
\hline
\end{tabular}

Sedangkan untuk nilai NDVI dibawah 0,1 dikategorikan dalam kelas non vegetasi. Berikut ini adalah hasil dari proses klasifikasi menggunakan software ENVI 5.3, setiap kelas memiliki warna yang berbeda. Dari hasil klasifikasi yang diperoleh kelas vegetasi dapat dikategorikan sebagai RTH baik RTH publik maupun RTH privat.

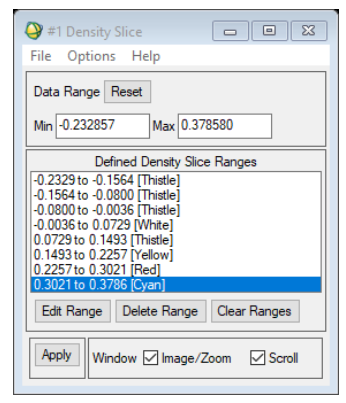

(a)

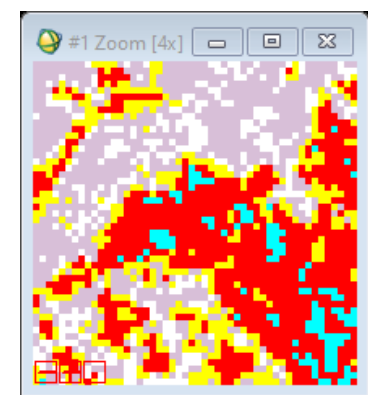

(b)
Gambar 4. Klasifikasi Citra (a) Pembagian Kelas, (b) Hasil Klasifikasi (zoom)

Dari gambar diatas menunjukkan bahwa warna Warna ungu muda (thistie) untuk kelas non vegetasi, warna kuning (yellow) untuk kelas vegetasi jarang, warna merah (red) untuk kelas vegetasi sedang, dan warna biru (cyan) untuk kelas vegetasi lebat. Kelas vegetasi jarang sebagian besar berupa rumput/lapangan golf/olahraga/area pemakaman/ persawahan terdapat pada rentang 0.2343-0.281, kelas vegetasi sedang sebagian besar berupa semak/tanaman perdu/rumput tinggi terdapat pada rentang 0.2814-3143, dan Kelas vegetasi lebat sebagian berupa tegakan pohon dari kanopi sedang hingga lebat/hutan kota/mangrove terdapat pada rentang $0.3144-0.6294$. Untuk kerapatan vegetasi yang dikategorikan sebagai RTH pada penelitian ini yaitu kelas vegetasi jarang-sedang dengan rentang nilai $0,2257-0,3021$ dan kelas vegetasi lebat dengan rentang nilai 0,3022-0,3786, untuk kelas vegetasi sangat tidak dikategorikan sebagai RTH karena nilai NDVI yang tidak termasuk dalam kategori[4].

6) Layout Peta

Berikut ini adalah hasil layout peta sebaran kerapatan vegetasi atau sebaran RTH di wilayah Kota Malang.

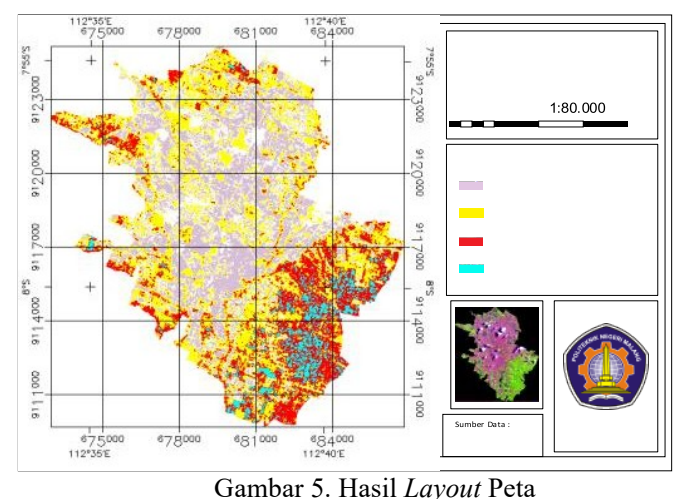

7) Menghitung Luas RTH

Untuk menghitung luas RTH menggunakan software ArcGIS 10.7 pada masing-masing kelas dilakukan calculate geometry. Setelah itu hasil luas RTH dapat dilihat pada nilai sum di menu statistic.

TABEL III

LUAS RTH DARI KERAPATAN VEGETASI KOTA MALANG 2016-2020

\begin{tabular}{|c|c|c|c|c|}
\hline Tahun & Vegetasi & $\begin{array}{c}\text { Luas } \\
\text { (ha) }\end{array}$ & $\begin{array}{c}\text { Presentase } \\
(\%)\end{array}$ & Total (\%) \\
\hline \multirow[b]{2}{*}{2016} & Sedang & 2128,95 & 14,652 & \multirow{2}{*}{17,818} \\
\hline & Lebat & 459,99 & 3,166 & \\
\hline \multirow[b]{2}{*}{2017} & Sedang & 1938,42 & 13,341 & \multirow[b]{2}{*}{15,571} \\
\hline & Lebat & 324,09 & 2,230 & \\
\hline \multirow[b]{2}{*}{2018} & Sedang & 2377,8 & 16,365 & \multirow[b]{2}{*}{27,925} \\
\hline & Lebat & 1679,76 & 11,561 & \\
\hline \multirow[b]{2}{*}{2019} & Sedang & 2007,45 & 13,816 & \multirow{2}{*}{17,434} \\
\hline & Lebat & 525,78 & 3,619 & \\
\hline \multirow[b]{2}{*}{2020} & Sedang & 1943,73 & 13,377 & \multirow[b]{2}{*}{17,182} \\
\hline & Lebat & 552,87 & 3,805 & \\
\hline
\end{tabular}

8) Uji Akurasi

Data citra hasil klasifikasi yang dianalisis adalah data terbaru dari satelit Landsat 8 yaitu data tanggal 25 Maret 2020, untuk survey lapangan dilakukan dengan memanfaatkan fitur Street View yang ada pada Google 
Maps dikarenakan uji lapangan secara langsung tidak memungkinkan untuk dilaksanakan pada bulan Maret 2020 hingga April 2020. Titik lokasi survey ditentukan secara acak (Random Sampling). Untuk memperoleh hasil akurasi yang cukup tinggi, penentuan titik survey disebar di setiap kecamatan wilayah Kota Malang yang terdiri atas lima kecamatan yaitu Kecamatan Sukun, Kecamatan Blimbing, Kecamatan Kedungkandang, Kecamatan Lowokwaru, dan Kecamatan Klojen diambil pada masing-masing kecamtan sebanyak 30 titik uji. Syarat yang digunakan untuk akurasi yaitu $>$ $70 \%$. Untuk mengetahui nilai presentase akurasi data dari hasil survey lapangan dapat menggunakan rumus berikut:

$\operatorname{Akurasi}(\%)=\frac{\text { jumlah data sesuai }}{\text { total banyaknya data }} \times 100 \%$

$\operatorname{Akurasi}(\%)=\frac{129}{150} \times 100 \%$

Akurasi $(\%)=86 \%$

Hasil perhitungan akurasi data yang diperoleh yaitu sebesar $86 \%$. Jadi, pada penelitian ini telah memenuhi syarat akurasi sehingga dapat dianggap benar. Berikut ini adalah beberapa gambar dari hasil survey lapangan:

TABEL IV

HASIL SURVEY LAPANGAN

\begin{tabular}{|c|c|c|}
\hline \multicolumn{2}{|c|}{ Koordinat } & \multirow{2}{*}{ Gambar Hasil Survey Lapangan } \\
\hline Latitude & Longitude & \\
\hline-7.971882 & 112.628596 & \\
\hline-7.967403 & 112.615038 & \\
\hline
\end{tabular}

C. Sistem Pendukung Keputusan (SPK)

Berikut ini adalah SPK yang dibuat dengan menggunakan metode SAW untuk hasil analisis tahun 2020: Kriteria :

C1 : Tutupan Non Vegetasi (\%) - (dari analisis pengolahan citra landsat 8)

C2 : Tutupan Non Vegetasi (\%) - (dari analisis uji akurasi)

C3 : Prioritas kebutuhan RTH

Sangat prioritas (1) dan cukup prioritas (2) Dari kriteria di atas $\mathrm{C} 1, \mathrm{C} 2$, dan $\mathrm{C} 3$ merupakan kriteria keuntungan/benefit.

Bobot untuk masing-masing kriteria sebagai berikut : $\mathrm{C} 1=$ $35 \%$; $\mathrm{C} 2=40 \%$; $\mathrm{C} 4=25 \%$.

Alternatif :
A1 : Kec. Blimbing A2 :

Kec. Sukun

A3 : Kec. Kedungkandang A4 :

Kec. Lowokwaru

A5 : Kec. Klojen

Nilai setiap alternatif adalah sebagai berikut :

TABEL V

NILAI ALTERNATIF

\begin{tabular}{cccc}
\multicolumn{4}{c}{ NILAI ALTERNATIF } \\
\hline Alternatif & C1 & C2 & C3 \\
\hline A1 & 76 & 43 & 2 \\
\hline A2 & 80 & 66 & 1 \\
\hline A3 & 53 & 36 & 2 \\
\hline A4 & 73 & 66 & 1 \\
\hline A5 & 80 & 70 & 1
\end{tabular}

Normalisasi (C1):

$$
\begin{gathered}
r_{11}=\frac{76}{\max \{76 ; 80 ; 53 ; 73 ; 80\}}=\frac{76}{80}=0,95 \\
r_{21}=\frac{80}{\max \{76 ; 80 ; 53 ; 73 ; 80\}}=\frac{80}{80}=1 \\
r_{31}=\frac{53}{\max \{76 ; 80 ; 53 ; 73 ; 80\}}=\frac{53}{80}=0,66 \\
r_{41}=\frac{73}{\max \{76 ; 80 ; 53 ; 73 ; 80\}}=\frac{73}{80}=0,91 \\
r_{51}=\frac{80}{\max \{76 ; 80 ; 53 ; 73 ; 80\}}=\frac{80}{80}=1
\end{gathered}
$$

Normalisasi (C2):

$$
\begin{gathered}
r_{14}=\frac{43}{\max \{43 ; 66 ; 36 ; 66 ; 70\}}=\frac{43}{70}=0,61 \\
r_{24}=\frac{66}{\max \{43 ; 66 ; 36 ; 66 ; 70\}}=\frac{66}{70}=0,94 \\
r_{34}=\frac{36}{\max \{43 ; 66 ; 36 ; 66 ; 70\}}=\frac{36}{70}=0,51 \\
r_{44}=\frac{66}{\max \{43 ; 66 ; 36 ; 66 ; 70\}}=\frac{66}{70}=0,94 \\
r_{54}=\frac{70}{\max \{43 ; 66 ; 36 ; 66 ; 70\}}=\frac{70}{70}=1
\end{gathered}
$$

Normalisasi (C3)

$$
r_{12}=\frac{2}{\max \{2 ; 1 ; 2 ; 1 ; 1\}}=\frac{2}{2}=1
$$




$$
\begin{aligned}
& r_{22}=\frac{1}{\max \{2 ; 1 ; 2 ; 1 ; 1\}}=\frac{1}{2}=0,5 \\
& r_{32}=\frac{2}{\max \{2 ; 1 ; 2 ; 1 ; 1\}}=\frac{2}{2}=1 \\
& r_{42}=\frac{1}{\max \{2 ; 1 ; 2 ; 1 ; 1\}}=\frac{1}{2}=0,5 \\
& r_{52}=\frac{1}{\max \{2 ; 1 ; 2 ; 1 ; 1\}}=\frac{1}{2}=0,5
\end{aligned}
$$

Hasil normalisasi:

$$
R=\left[\begin{array}{ccc}
0,95 & 0,61 & 1 \\
1 & 0,94 & 0,5 \\
0,66 & 0,51 & 1 \\
0,91 & 0,94 & 0,5 \\
1 & 1 & 0,5
\end{array}\right]
$$

Proses perangkingan dengan menggunakan bobot yang telah ditentukan :

$$
\mathrm{W}=\left[\begin{array}{lll}
0,35 & 0,4 & 0,25
\end{array}\right]
$$

Hasil yang diperoleh adalah sebagai berikut:

$$
\begin{aligned}
\mathrm{V} 1 & =(0,35)(0,95)+(0,4)(0,61)+(0,25)(1)=0,82 \\
\mathrm{~V} 2 & =(0,35)(1)+(0,4)(0,94)+(0,25)(0,5)=0,85 \\
\mathrm{~V} 3 & =(0,35)(0,66)+(0,4)(0,51)+(0,25)(1)=0,68 \\
\mathrm{~V} 4 & =(0,35)(0,91)+(0,4)(0,94)+(0,25)(0,5)=0,81 \\
\mathrm{~V} 5 & =(0,35)(1)+(0,4)(1)+(0,25)(0,5)=0,87
\end{aligned}
$$

Dari hasil perangkingan dari perhitungan di atas menunjukkan nilai terbesar ada pada V5 sehingga alternatif A5 adalah alternatif yang terpilih sebagai alternatif paling atas. Dengan kata lain rekomendasi keputusan dari hasil analisis di tahun 2020 adalah Penambahan RTH paling dibutuhkan adalah di kecamatan Klojen kemudian kecamatan Sukun selanjutnya kecamatan Blimbing.

\section{Aplikasi Android}

Setelah melakukan pengolahan data citra satelit landsat 8 untuk mengetahui kerapatan RTH di wilayah kota malang, hasil data yang diperoleh kemudian dijadikan sumber informasi dengan dibuat aplikasi berbasis android sehingga pemerintah maupun masyarakat umum dapat mengakses informasi seputar RTH diwilayah kota malang melalui aplikasi tersebut. Aplikasi tersebut berisi informasi RTH dan rekomendasi Tindakan untuk pengelolaan RTH di wilayah kota malang. Dengan tujuan untuk menjaga dan meningkatkan keberadaan RTH diwilayah kota malang.

Berikut ini adalah hasil dari aplikasi android yang telah dibuat.

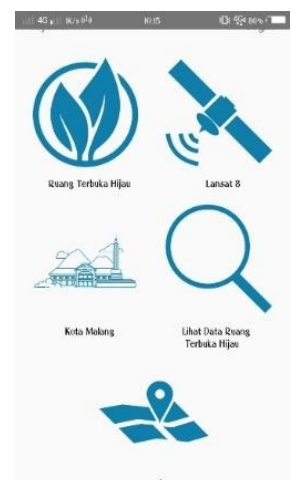

Gambar 6. Tampilan halaman awal aplikasi android

Ketika user telah memilih data pada tahun yang ingin dilihat, informasi yang dimuat adalah tahun, luas RTH (ha), luas RTH(\%), saran/ rekomendasi keputusan dan gambar peta kota malang yang telah diolah. Rekomendai keputusan yang dibuat adalah sebagai berikut:

- Apabila luas vegetasi lebat $<10 \%$ maka, Tindakan yang perlu dilakukan adalah penambahan RTH publik berupa hutan kota dan taman RT/ RW

- Apabila luas vegetasi lebat $>10 \%$ maka, Tindakan yang perlu dilakukan adalah menjaga ketersediaan RTH khususnya RTH privat baik milik perorarangan maupun instansi

Agar aplikasi android yang dibuat lebih informatif maka ditambahkan juga akses untuk melihat peraturan zonasi wilayah Kota Malang, informasi ini bertujuan agar user bisa mengetahui tentang zona perumahan, perkantoran, hutan kota dsb. Untuk mengakses informasi ini pilih icon Rencana Detail Tata Ruang (RDTR) di menu uatama, icon tersebut akan dihubungkan pada alamat tautan http://gistaru.atrbpn.go.id/rdtrinteraktif/ yang mana merupakan milik Direktorat Jenderal Tata Ruang Kementerian Agraria dan Tata Ruang / Badan Pertahanan Nasional maka akan muncul tampilan berikut, pilih 'Setuju dan Lanjutkan'.

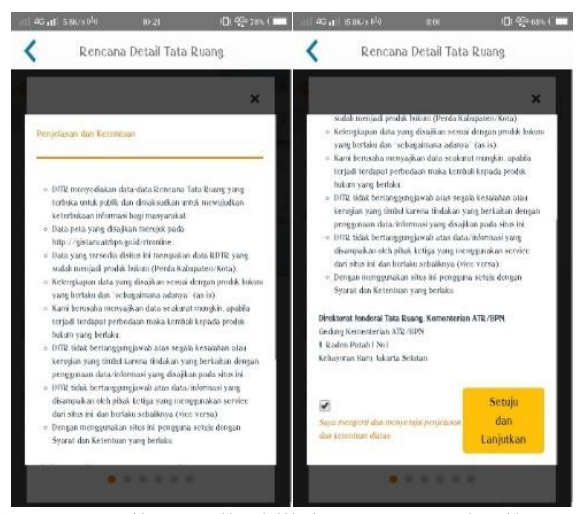

Gambar 7. Tampilan Ketika klik icon rencana detail tata ruang 


\section{KESIMPULAN}

\section{A. Kesimpulan}

Kesimpulan yang diperoleh dari penelitian yang dilakukan adalah sebagai berikut :

1) Metode NDVI dapat digunakan untuk memperoleh informasi tentang RTH di wilayah Kota Malang dengan sumber data citra Satelit Landsat 8 dengan keakurasian data sebesar $86 \%$.

2) Sistem Pendukung Keputusan yang dibuat berdasarkan analisis citra tahun 2020 menghasilkan rekomendasi keputusan Penambahan RTH diperlukan di 3 kecamatan yaitu Kecamatan Klojen, Kecamatan Sukun dan Kecamatan Blimbing yang mana membutuhkan tindakan untuk meningkatkan tutupan vegetasi di daerah tersebut.

Dari analisis penelitian yang memanfaatkan Satelit Landsat 8 diperoleh luasan RTH berdasarkan kerapatan vegetasi, data yang dianalisis merupakan data dari tahun 2016 sampai dengan tahun 2020. Pada tahun 2016 total luasan RTH yaitu 2588,94 ha atau hanya sebesar 17,81\% dari luas total Kota Malang, tahun 2017 luasan RTH mengalami penurunan yaitu sebesar 2262,51 ha atau hanya $15,57 \%$ dari luas total Kota Malang, tahun 2018 terdapat perningkatan yang cukup signifikan luas RTH sebesar 4057,56 ha atau $27,92 \%$ dari luas total Kota Malang, tahun 2019 luas RTH hanya sebesar 2533,23 ha atau $17,43 \%$ dari luas total Kota Malang, dan pada tahun 2020 luas RTH yaitu sebesar 2496,6 ha atau 17,18\% dari luas total Kota Malang

Aplikasi android yang dibuat adalah untuk memberikan rekomendasi tindakan yang perlu dilakukan untuk meningkatkan luas RTH di wilayah Kota Malang, rekomendasi tindakan diutamakan pada sosialisasi tentang pentingnya keberadaan RTH kepada masyarakat luas selain itu pihak pemerintahan terkait juga perlu melakukan pengkajian lebih detail mengenai pengembangan RTH khususnya di daerah yang sangat padat penduduk, selain itu juga ditambahkan akses untuk mengetahui Peraturan Zonasi dengan menghubungkan pada tautan yang disediakan oleh Direktorat Jenderal Tata Ruang Kementerian Agraria dan Tata Ruang / Badan Pertahanan Nasional.

B. Saran

Dari penelitian yang telah dilakukan diperoleh beberapa saran sebagai berikut

1) Untuk penelitian selanjutnya agar memperoleh hasil yang lebih akurat maka diperlukan penelitian dengan menggunakan metode lain selain metode NDVI, selain itu jugu diperlukan penelitian yang lebih spesifik dengan membuat penelitian secara merinci di setiap kecamatan di wilayah Kota Malang.

2) Untuk mewujudkan peningkatan luas RTH di wilayah Kota Malang diperlukan kerjasama dari semua pihak, mulai dari pemerintah terkait hingga masyarakat pada umumnya dalam rangka menjaga, mengelola, dan meningkatkan RTH agar tercipta kelestarian lingkungan yang sehat dan berkelanjutan.

\section{REFERENSI}

[1] R. Dwihatmojo, "PenataanRuang.Com," Badan Inf. Geospasial, 2016, doi: 10.1007/s00205-016-1019- 6.

[2] M. Iqbal, "Pengelolaan Ruang Terbuka Hijau Berdasarkan Peraturan Daerah Kota Padang No 3 Tahun 2017," no. 3, 2019.

[3] A. malik, Pengelohan Citra Digital dengan ER Mapper ver 7.0, September, 2016.

[4] S.N. Lufilah et al., "Pemanfaatan Citra landsat 8 untuk Analisis Indeks", 2016. 